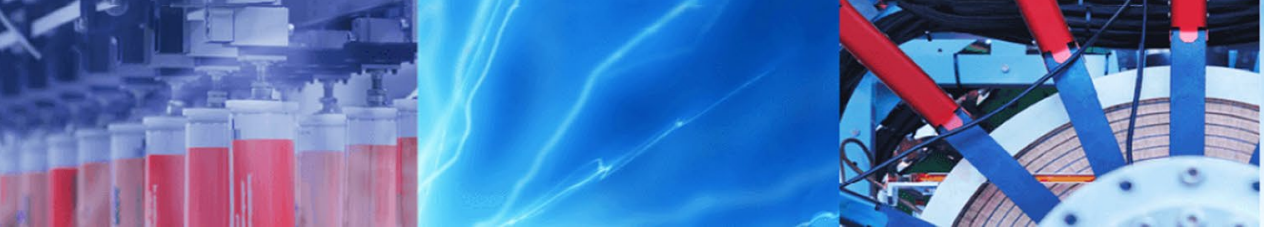

Research Article

\title{
Metallic oxide-graphene composites as a catalyst for gas-phase oxidation of benzyl alcohol to benzaldehyde
}

\author{
Ruibing $\mathrm{Li}^{1} \cdot$ Wenjun Cheng ${ }^{2} \cdot$ Yunong $\mathrm{Yan}^{2} \cdot \mathrm{Ying} \mathrm{Shi}^{2} \cdot \operatorname{Linlin} \mathrm{Wei}^{2} \cdot$ Sansan $\mathrm{Yu}^{2} \mathbb{C} \cdot$ Shuangming $\mathrm{Li}^{2}$
}

Received: 4 January 2021 / Accepted: 8 March 2021 / Published online: 20 March 2021

(C) The Author(s) 2021 OPEN

\begin{abstract}
A new catalyst (FAG) composed of $\mathrm{Fe}, \mathrm{Al}$, and graphene (G) was prepared for catalyzing the reaction of benzyl alcohol (BA) to benzaldehyde (BD). The catalyst was characterized by XRD, XPS, SEM, and BET analyses. The catalytic performance of FAG for oxidation of BA to BD was studied by comparing with the catalysts ferrous oxide (Fe), ferrous oxide doped with aluminum ( $F A)$, and ferrous oxide doped with graphene (FG). The effects of amount of graphene additive, temperature, and ratio of Fe and Al were also studied. The results show that the catalyst FAG has a great specific surface area of $80.40 \mathrm{~m}^{2} \mathrm{~g}^{-1}$ and an excellent catalytic performance for the reaction of BA to BD: the conversion of BA and yield of BD significantly increased, and the selectivity of BD reached $87.38 \%$.
\end{abstract}

Keywords Supercritical · Selective oxidation · Alcohol · Metallic oxide-graphene composites · Catalyst

\section{Introduction}

Selective oxidation of alcohols such as benzyl alcohol (BA) to the corresponding aldehydes involving the cleavage of $\mathrm{O}-\mathrm{H}$ bonds followed by $\mathrm{a}-\mathrm{C}-\mathrm{H}$ bond activation is a typical process in fine chemicals industry. In the past several years, several catalysts have been used for the selective oxidation of alcohols, such as noble metal coordination compounds ( $\mathrm{Pd}, \mathrm{Ru}, \mathrm{Au}, \mathrm{Pt})[1-3]$, non-noble metal oxides $[4,5]$, organometallic compounds [6, 7], inorganic oxidants (manganese dioxide, Sarett reagent, Jones reagent) [8, 9], heteropolyacid catalysts [10,11], and ionic liquids [12]. The oxidation activity of catalysts of these noble metal nanoparticles is higher for catalyzing BA. The metal nanoparticles have particular chemical and photoelectric properties, but they can be easily combined to form a big particle due to the electrostatic interaction between the particles. Thus, the exposure level of active site decreases, and its activity also decreases. Because of the size effect, aggregation of metal particles during reaction, and decrease in the exposure level of active site, the stability and life of catalyst is not satisfactory.

Loading a noble metal to a carrier, such as loading $\mathrm{Ru}$ to $\mathrm{TiO}_{2}, \mathrm{ZrO}_{2}$, and carbon $[13,14]$ and loading $\mathrm{Au}$ to $\mathrm{Al}_{2} \mathrm{O}_{3}$, $\mathrm{SiO}_{2}$, and $\mathrm{TiO}_{2}[15,16]$, can increase the metal particle dispersity, prevent the carbon deposition and favor the contact of reactant with the active site, and further increase the stability and catalytic activity of catalyst. However, noble metal particle catalysts are expensive and suffer from low utilization and difficulty in recycling. Over the years, many efforts have been made to prepare non-noble metal catalysts $[6,17]$.

In the past decades, carbon-based materials including graphene, carbon nanotubes, and nanodiamonds have attracted much attention because of their high specific surface area, high conductivity, feasible surface modification, and eco-friendly continuous large-scale preparation [18-22]. Among them, graphene with a hexagonal

$\triangle$ Sansan Yu, ssyu@syuct.edu.cn; $\bowtie$ Shuangming Li, lishuangming@syuct.edu.cn | 1 School of Mechanical and Power Engineering, Shenyang University of Chemical Technology, Shenyang 110142, China. ${ }^{2}$ School of Chemical Engineering, Shenyang University of Chemical Technology, Shenyang 110142, China. 
honeycomb structure, two-dimensional (2D) nanocarbon material stacked from carbon atoms by $\mathrm{sp}^{2}$ hybridization has a unique conjugate electronic structure, i.e., melectronic structure, that promotes strong interactions with various reactants, especially compounds with a benzene ring [23].

Graphene, a carbon-based material with a single layer of $\mathrm{sp}^{2}$-bonded carbon atoms arranged in a hexagonal honeycomb structure, mainly contains a graphite skeleton, defects, and oxygen-containing groups. The oxygencontaining groups can be a weak acid, and it can catalyze acid-base reactions. The $O$ in the oxygen-containing group acts as an intermediate oxygen species and catalyzes the reaction with a stronger oxidizing ability. The defects in graphene not only activates the oxygen molecules, but also decomposes the reducing agent, such as hydrazine hydrate [23]; thus, they can catalyze simple reduction reactions. Yang et al. [24] used graphene as a catalyst and aqueous hydrogen peroxide solution as an oxidizing agent to catalyze the oxidation of benzene to phenol. The results show that graphene has good selectivity of phenol, i.e., $99 \%$, and the conversion of benzene is $18 \%$. The catalyst has a good lifetime and does not deactivate even after seven times of circulation.

In the past few years, graphene and doped and modified graphene have been used as a nonmetal catalyst to catalyze the oxidation of $B A$ to benzaldehyde (BD), thus oxidizing BA to BD with high selectivity. Wang et al. [25] used nitrogen-doped graphene to catalyze the oxidation of $\mathrm{BA}$ to $\mathrm{BD}$ at $80^{\circ} \mathrm{C}$ temperature and $0.1 \mathrm{MPa}$ pressure, achieving a $\mathrm{BA}$ conversion of $12.8 \%$ and $\mathrm{BD}$ selectivity of up to $100 \%$. They proposed that the graphite type nitrogen $\left(\mathrm{sp}^{2} \mathrm{~N}\right)$ is the active site of catalytic reaction. Dynamic study shows that when nitrogen-doped graphene is used as a catalyst, the activation energy of reaction is $56.1 \mathrm{~kJ} \mathrm{~mol}^{-1}$, close to one of the traditional noble metal loaded catalyst, $51.4 \mathrm{~kJ} \mathrm{~mol}^{-1}$. Cheng et al. [26] used boron-doped graphene as a metal-free catalyst in the gasphase oxidation of BA to BD and achieved excellent performance with selectivity of BD of up to $99.2 \%$.

Using graphene as a carrier to form a composite with metal particles, the combination of metal nanoparticles can be decreased. The nanoparticles can decrease the interaction between graphene layers. The metal matrix particles used in the composites of metal nanoparticles with graphene are mainly noble metals $\mathrm{Pt}$ and $\mathrm{Au}$, and some transition metals and their oxides. The composites showed excellent performance compared to nanocomposite metal particles. Huang et al. [27] prepared a Pt-graphene composite using a soft chemical method. This method is simple, and the graphene structure is not damaged. The composite exhibited excellent electrochemical activity and good toxic tolerance. Zheng et al.
[28] prepared a Ag-graphene composite where the $\mathrm{Ag}$ particles were uniformly dispersed on graphene, and a capacitance electricity of up to $220 \mathrm{~F} \mathrm{~g}^{-1}$ was achieved. The Ag-graphene composite has a good application prospect in the field of electrode energy storage and conversion. Jiang et al. [29] prepared a Fe-graphene nanomaterial using supercritical $\mathrm{CO}_{2}$ fluid method. The particle diameter is $2 \mathrm{~nm}$. and the Fe nanoparticles were dispersed on graphene with a high degree of dispersion. The Fe-graphene nanomaterial was used as a catalyst in dehydrogenation reaction of lithium aluminum tetrahydride and exhibited good catalytic activity. Without changing the reaction path, the dehydrogenation temperature of Fe-graphene composite was about $40{ }^{\circ} \mathrm{C}$ lower than before, and hydrogen with $4.5 \%$ mass fraction can be completely decomposed in $6 \mathrm{~min}$ at $100^{\circ} \mathrm{C}$. Moma et al. [30] synthesized Al/ Fe pillared clay from natural bentonite clay and used as a catalyst in the catalytic wet-air oxidation of phenol. It was found to be highly active and stable with superior properties such as surface areas, basal spacing, high porosity, and thermal stability.

In this study, an Al-Fe composite doped with graphene (FAG) was evaluated for the gas-phase oxidation of BA to $\mathrm{BD}$. The catalyst was characterized by XRD, XPS, SEM, and BET analyses, and the effects of additive amount of graphene, $\mathrm{Al} / \mathrm{Fe}$ ratio, and preparation conditions temperature, pressure, and space velocity were evaluated.

\section{Experimental}

\subsection{Preparation of catalyst}

Graphite oxide (GO, 96.0\%, mass fraction) was supplied by Jining Leader nano Technology Co., LTD., Shandong, China. GO was prepared from natural graphite using a modified Hummers method [31, 32]. The composites of ferric oxide with graphene $(\mathrm{FG})$ and $\mathrm{Fe}-\mathrm{Al}$ oxide with graphene (FAG) were synthesized using supercritical (subcritical) fluid method in an autoclave at 300,350 , and $400{ }^{\circ} \mathrm{C}$ for $1 \mathrm{~h}$. In a supercritical solvent with high super saturation, uniform conditions were rapidly attained, and highly crystallized nano-sized oxide particles were obtained. This technique has the advantages of simple and short time for preparation, and it has been extensively used to successfully synthesize various metal oxides with fine control over chemical and phase compositions, size, morphology, and structure [33].

In a typical procedure for FAG preparation, GO was added to alcohol in an ultrasonic cleaner for $1 \mathrm{~h}$ while the $\mathrm{GO}$ was dispersed in alcohol uniformly. Then, ferric nitrate and aluminum nitrate were added, and the mixture was stirred for $2 \mathrm{~h}$ while they mixed well and then placed in 


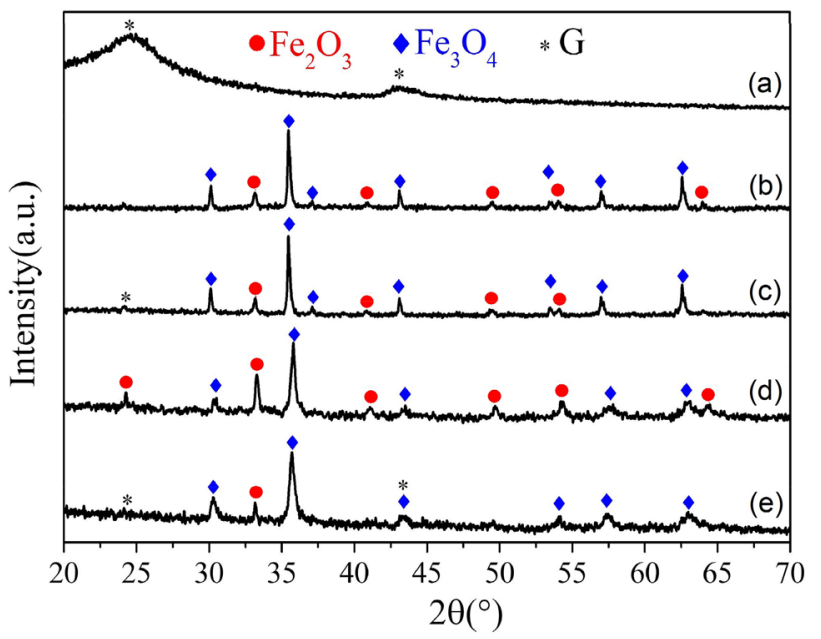

Fig. 1 XRD results: (a) G, (b) Fe, (c) FG, (d) FA, and (e) FAG

an autoclave at a set temperature for $1 \mathrm{~h}$. The obtained products were then washed with alcohol and water to eliminate the unreacted materials while the products had no color. Finally, the products were dried at $60^{\circ} \mathrm{C}$ for $24 \mathrm{~h}$.

\subsection{Analytical equipment}

A D8 Advance X-ray generator (Bruker AXS Company, Germany) with $\mathrm{Cu}$ Ka1 radiation was used to identify the structure and purity of products, The X-ray intensity was measured over a $2 \theta$ diffraction angle from $10^{\circ}$ to $90^{\circ}$ with a step size of $0.02 \%$ min. An S-4800 scanning electron microscope (SEM) (Hitachi Ltd., Japan) and S-Twin transmission electron microscope (TEM) (TECNAI G² F20, FEI Company,

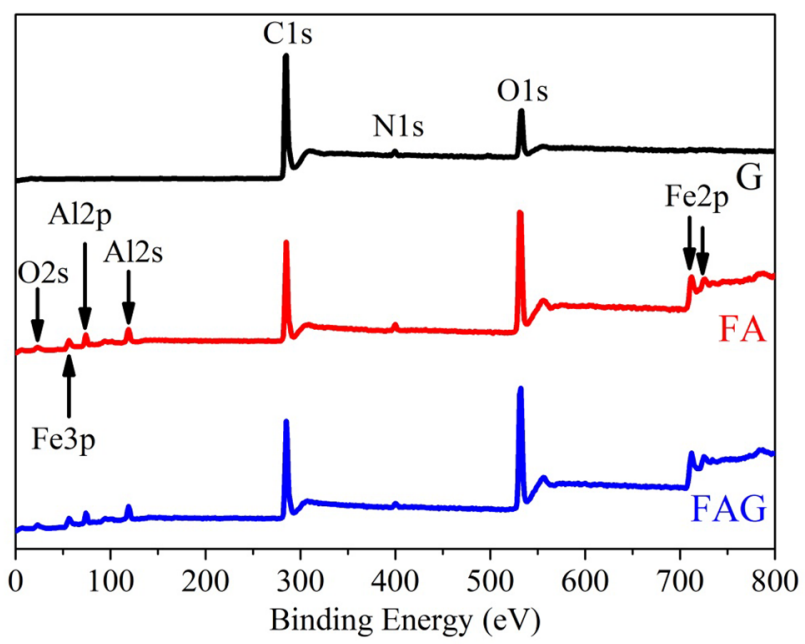

Fig. 2 XPS survey spectrum for G, FA, and FAG
USA) were used to observe the morphologies of catalysts. The SEM and TEM images were obtained at an accelerating voltage of 10 and $200 \mathrm{kV}$, respectively. The surface area of catalyst was analyzed using an Auto sorb-iQ system (Quanta chrome, USA) using Brunauer-Emmett-Teller (BET) method and nitrogen adsorption-desorption isotherms at a liquid nitrogen temperature of $77 \mathrm{~K}$. The surface composition of synthesized materials was analyzed by X-ray photoelectron spectroscopy (XPS) (ESCALAB250, Thermo Electron Corporation, USA). The conversion and selectivity was analyzed by GC7900 gas chromatography (Shanghai Techcomp Instrument Ltd.) and Agilent 1260 liquid chromatography (Agilent Technologies Inc. USA).

\subsection{Measurement of catalytic performance}

The oxidation performance of catalyst was evaluated experimentally in a gas-phase fixed-bed reactor with $100 \mathrm{mg}$ of each catalyst. The reactor was heated under

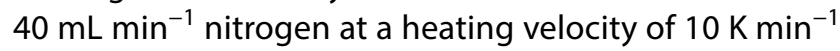
until the set reaction temperature reached. The feed comprising $\mathrm{BA}$ and oxygen $\left(\mathrm{n}_{\mathrm{O} 2} / \mathrm{n}_{\mathrm{BA}}=2\right)$ in nitrogen $\left(\mathrm{n}_{\mathrm{N} 2} /\right.$ $n_{B A}=6.2$ ) was added to the reactor at a total flow rate of

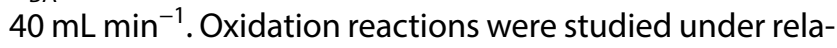
tively gentle conditions (493, 523, and $553 \mathrm{~K}$ ). The liquidphase product obtained after cooling through a cryogenic circulation tank was sampled periodically and analyzed by high-performance liquid chromatography (HPLC, Agilent 1260, USA) equipped with an Agilent Zorbax SB-C18 column. Methyl BA was added as the internal standard to the collected liquid product for qualitative and quantitative analyses. The mobile phase is chromatographic-grade acetonitrile and ultrapure water $\left(30: 70,40{ }^{\circ} \mathrm{C}\right)$. The reaction tail gas was monitored using an online gas chromatograph (Tech comp GC7980, China) equipped with a thermal conductivity detector (TCD) and Porapak-Q column. Blank experiments without carbon catalyst showed that the reaction conversion was negligible $(<0.2 \%)$.

\section{Results and discussion}

\subsection{Characterization of catalysts}

Figure 1 shows the XRD patterns of catalysts including graphene $(G)$, ferrous oxide (Fe), ferrous oxide doped with graphene (FG), ferrous oxide doped with aluminum (FA), and FAG made from GO, aluminum nitrate, ferric nitrate, and alcohol (Table 2). Pattern (a) shows two broad diffraction peaks at $24.6^{\circ}(\mathrm{d}=0.34 \mathrm{~nm})$ and $43.0^{\circ}(\mathrm{d}=0.21 \mathrm{~nm})$ for $\mathrm{G}$. Cheng et al. [26] reported an intense and sharp reflection centered at $11^{\circ}$ for $\mathrm{GO}$, corresponding to a c-axis 
Fig. 3 High-resolution spectra: a samples $\mathrm{G}$ for $\mathrm{C} 1 \mathrm{~s} ; \mathbf{b}$ and $\mathbf{c}$ samples $\mathrm{FA}$ with the $\mathrm{Fe}$ and $\mathrm{Al}$ ratio of $2: 1$ for Fe $2 p$ and $A I 2 p$, respectively; $\mathbf{d}, \mathbf{e}$, and $\mathbf{f}$ samples $\mathrm{FAG}$ with the $\mathrm{Fe}, \mathrm{Al}$, and $\mathrm{G}$ ratio of 2:1:0.32 for C1s, Fe2p, and $\mathrm{Al} 2 \mathrm{p}$, respectively

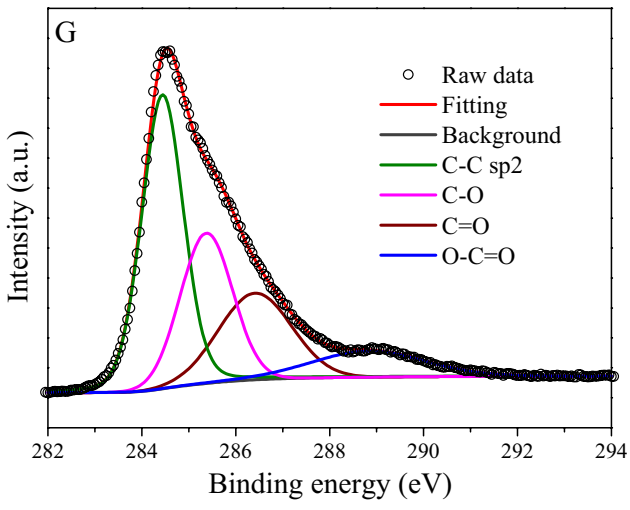

(a)

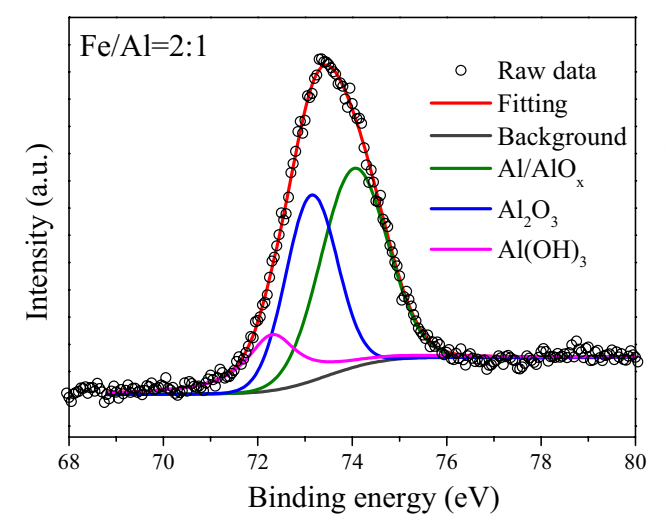

(c)

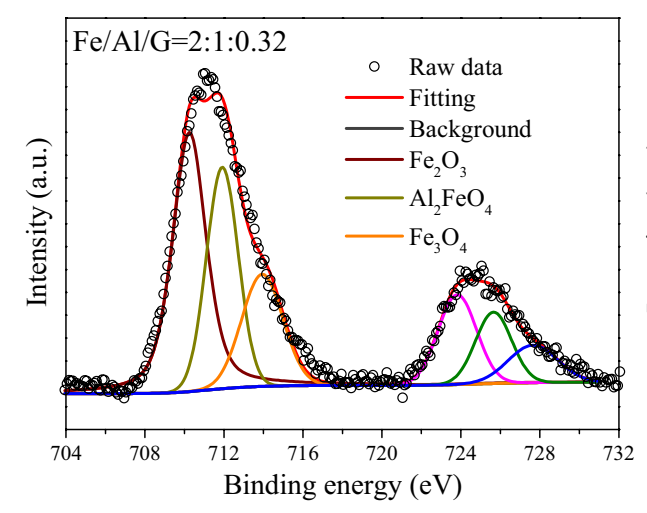

(e)

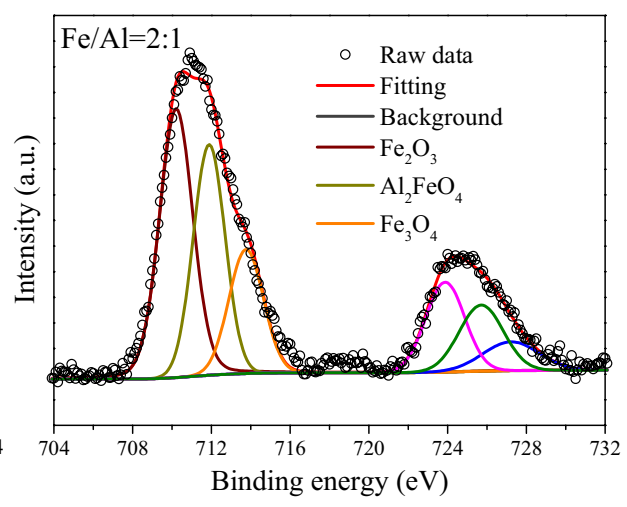

(b)

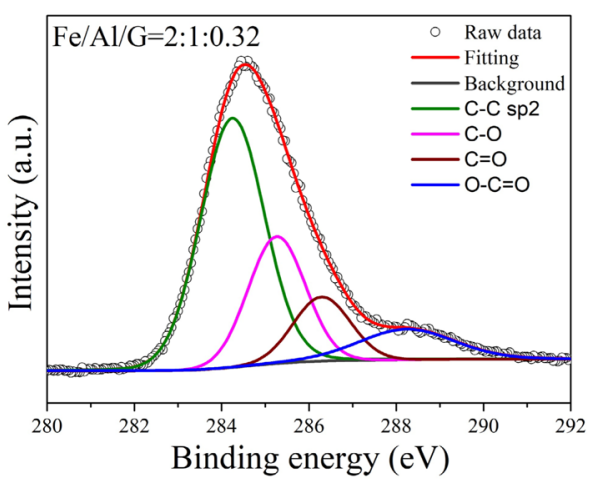

(d)

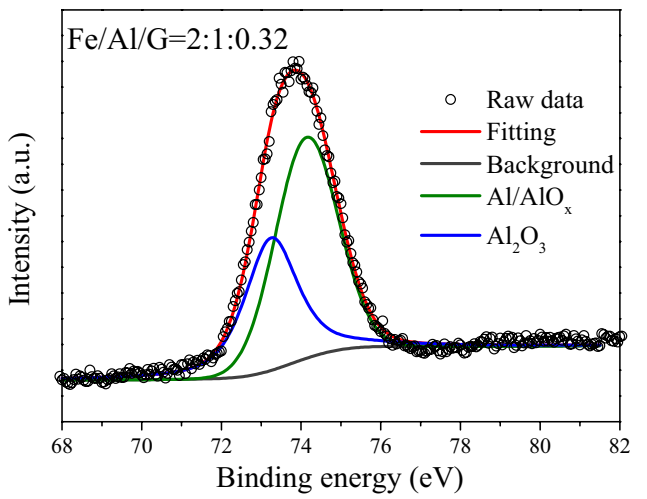

(f) interlayer spacing of $0.81 \mathrm{~nm}$ [25]. The characteristic peak of $\mathrm{GO}$ disappeared since it underwent thermal processing in Ar atmosphere at $1173 \mathrm{~K}$ for $2 \mathrm{~h}$, confirming that most of the oxygen-containing functional groups in $\mathrm{GO}$ were detached under the supercritical condition with high temperature and high pressure. The graphene lamella was replied, and the interlayer space was reduced [32, 34]. Thus, successful conversion of GO to graphene was achieved [35]. This indicates that GO cannot be completely and uniformly exfoliated by the interlayer expansion along the c-axis direction at such a temperature, leading to the formation of multilayer graphene nanosheets [25].

The Fe catalyst is composed of $\mathrm{Fe}_{3} \mathrm{O}_{4}$ and $\mathrm{Fe}_{2} \mathrm{O}_{3}$ (Pattern (b)). When $\mathrm{G}$ is added, the diffraction peaks are not changed, indicting that the $G$ does not lead to a phase composition change for the metal oxide. The small peak at $24.6^{\circ}$ confirms the successful formation of composite of $\mathrm{G}$ with metal oxide (Pattern (c)). When aluminum was 


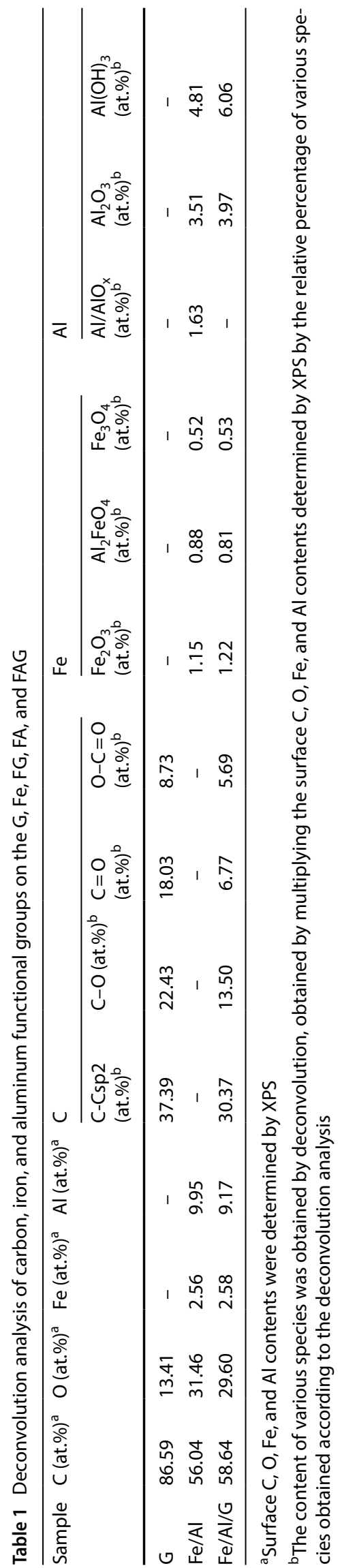

added to Fe catalyst, the diffraction peaks still correspond to $\mathrm{Fe}_{3} \mathrm{O}_{4}$ and $\mathrm{Fe}_{2} \mathrm{O}_{3}$ (Pattern (d)), but XPS detection verified that aluminum exists (Fig. 2). When FA was added to $\mathrm{G}, \mathrm{Fe}_{3} \mathrm{O}_{4}$ became the main content with a small amount of $\mathrm{Fe}_{2} \mathrm{O}_{3}$, indicating that the phase composition changed under the effect of aluminum and G (Pattern (e)). Using Debye-Scherrer method, the particle diameter of FAG was found to be $16 \mathrm{~nm}$, compared to FA of $21 \mathrm{~nm}$ and both Fe and FG of $\sim 39 \mathrm{~nm}$, indicating that FAG decreases the mutual friction between metal particles and also decreases the size of nanoparticles.

The XPS survey spectrum shows a weak N1s signal in the three patterns because the samples were exposed to atmosphere and adsorbed the nitrogen in air (Fig. 2). Figure 3 shows the high-resolution spectra of samples $G$ and $F A$ with $F e$ and Al ratio of 2:1 and FAG samples with $\mathrm{Fe}, \mathrm{Al}$, and $\mathrm{G}$ ratio of 2:1:0.32. Figure 3a shows that most of oxygen in graphene is detached after it is handled under supercritical condition of high temperature. The oxygen content is only $13.41 \%$ (Table 1 ). The oxygen-containing functional groups mainly exist in three forms of $\mathrm{C}-\mathrm{O}$, $\mathrm{C}=\mathrm{O}$, and $\mathrm{O}-\mathrm{C}=\mathrm{O}$ (Fig. 3a). The carbon in graphene is mainly combined with the oxygen of oxygen-containing functional groups. The amount of $\mathrm{C}-\mathrm{C} \mathrm{sp^{2 }}$ in graphene is $37.39 \%$ (Table 1).

The amounts of Fe and $\mathrm{Al}$ in the samples FA and FAG have not much difference after handled under the supercritical condition. In the sample FAG, most carbon corresponds to the graphite in graphene, $30.37 \%$, and ketone carbonyl is the main form of oxygen-containing functional groups, $6.77 \%$ (Table 1). The main forms of $\mathrm{Fe}$ in the sample $\mathrm{FA}$ is $\mathrm{Fe}_{2} \mathrm{O}_{3}$ and $\mathrm{Al}_{2} \mathrm{FeO}_{4}$, and those in the sample $\mathrm{FAG}$ is also $\mathrm{Fe}_{2} \mathrm{O}_{3}$ and $\mathrm{Al}_{2} \mathrm{FeO}_{4}$ (Fig. $3 \mathrm{~b}$, e). $\mathrm{Al}$ in the FA sample mainly exists in three forms $\mathrm{Al} / \mathrm{AlO}_{x}, \mathrm{Al}_{2} \mathrm{O}_{3}$, and $\mathrm{Al}(\mathrm{OH})_{3}$, and $\mathrm{Al}$ in the $\mathrm{FAG}$ sample mainly exists in two forms $\mathrm{Al}_{2} \mathrm{O}_{3}$ and $\mathrm{Al} / \mathrm{AlO}_{\mathrm{x}}$ (Fig. $3 \mathrm{C}$, f). In the XPS measurement, the sample need to handle specially, otherwise, the surface of sample is easy to adsorb $C$ and $O$, the peaks of $C$ and $O$ will appear in the results. The height of the peaks involve with the properties of the sample and the exposing time. Since the sample is not handled specially, C content is appeared in FA (Table 1).

Figure 4 shows the SEM images of G, Fe, FG, FA, and FAG. Figure 4a shows a lamellar structure with mist-like 
Fig. 4 SEM images: a G, b Fe, c FG, d FA, and e FAG

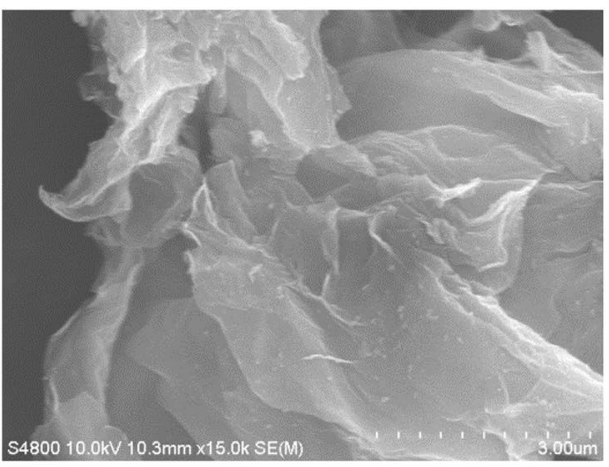

(a)

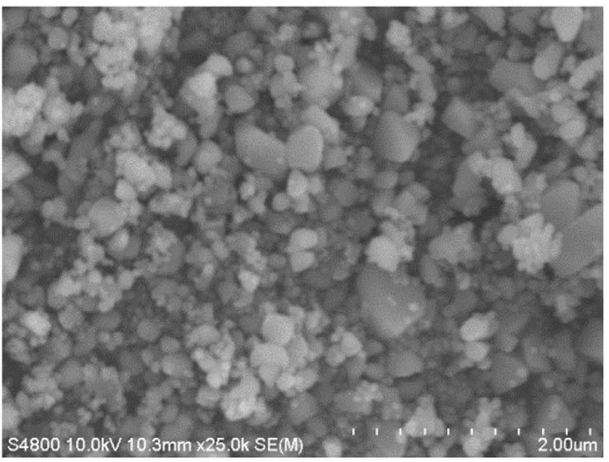

(c)

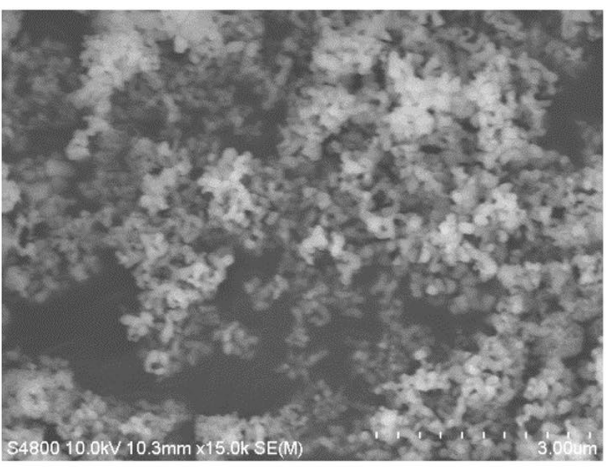

(b)

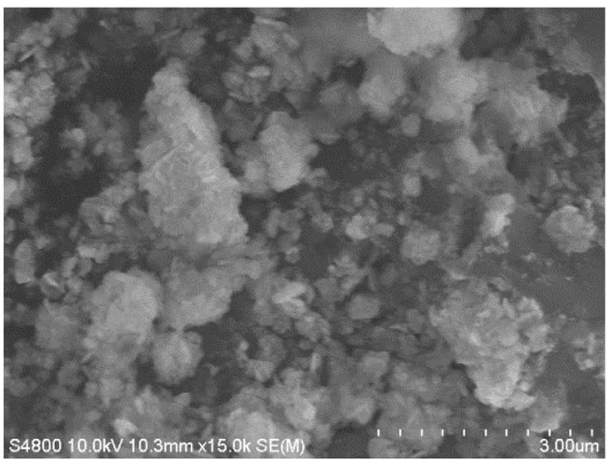

(d)

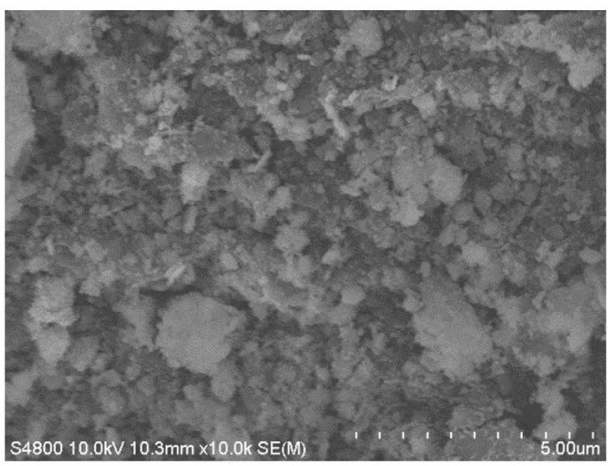

(e)

and wrinkle on the surface for the $G$ sample obtained under supercritical condition. Thus, the GO sample can be detached and stripped to a lamellar structure [36]. Figure $4 b$ shows that the Fe particles have uniform distribution and exist in clusters. When Fe is combined with graphene, the morphology of particles is distributed in cubes and spheres (Fig. 4c). The image of FA shows a severe particle agglomeration (Fig. 4d), and the image of FAG shows a big block and lamellar structure (Fig. 4e).

The BET specific surface area was obtained from the nitrogen adsorption-desorption isotherms measured at a temperature of $-196^{\circ} \mathrm{C}$ (Fig. 5). In the nitrogen adsorption-desorption isotherms, an obvious hysteresis loop observed between 0.45 and $0.98 \mathrm{p} / \mathrm{p}_{0}$ (Fig. 5a). Since different scales are used in Fig. 5a, the specific surface area not 


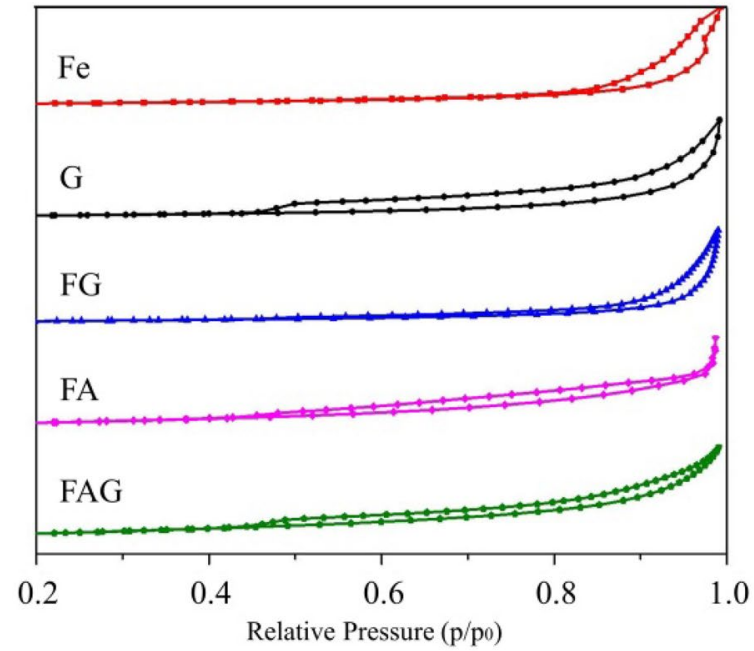

(a)

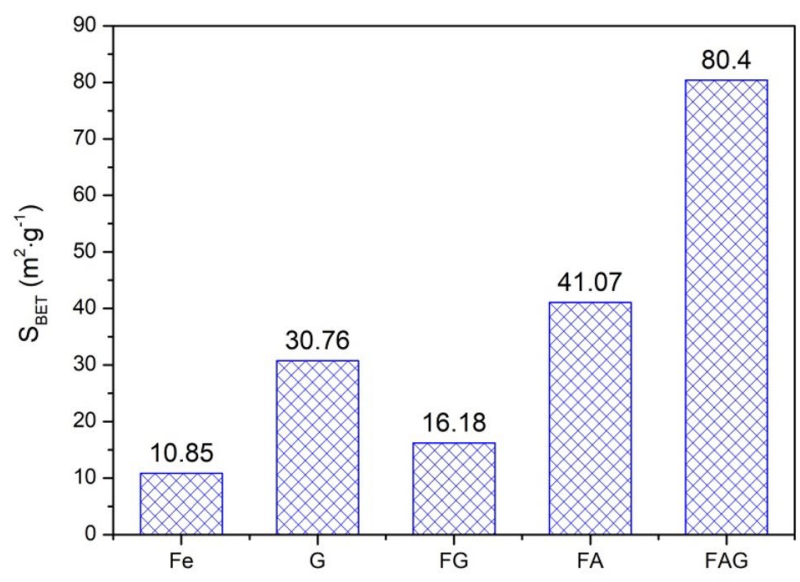

(b)

Fig. 5 BET analysis: a Nitrogen adsorption-desorption isotherms, $\mathbf{b}$ specific surface area of $\mathrm{Fe}, \mathrm{G}, \mathrm{FG}, \mathrm{FA}$, and FAG be shown. Figure $5 \mathrm{~b}$ shows that the specific surface area of $G$ obtained under supercritical condition is $30.76 \mathrm{~m}^{2} \mathrm{~g}^{-1}$ and that of Fe is $10.85 \mathrm{~m}^{2} \mathrm{~g}^{-1}$. When Fe is doped with $\mathrm{G}$, its specific surface area increased, $16.18 \mathrm{~m}^{2} \mathrm{~g}^{-1}$ for $F G$ and $41.07 \mathrm{~m}^{2} \mathrm{~g}^{-1}$ for FA. When FA is doped with $\mathrm{G}$, the specific surface area significantly increased to $80.40 \mathrm{~m}^{2} \mathrm{~g}^{-1}$, indicating that the specific surface area can be effectively increased by adding $G$ into FA. When the same amount of $\mathrm{G}$ was added to $\mathrm{Fe}$ without $\mathrm{Al}$, the specific surface area did not increase much, from 10.85 to $16.18 \mathrm{~m}^{2} \mathrm{~g}^{-1}$. When Al exists in the catalyst, the specific surface area increased much more, up to $80.40 \mathrm{~m}^{2} \mathrm{~g}^{-1}$. Thus, it is concluded that when $\mathrm{Al}, \mathrm{Fe}$, and $\mathrm{G}$ exist at the same time, the specific surface area can be significantly increased.

\subsection{Catalytic performance}

\subsubsection{Comparison between $\mathrm{G}, \mathrm{Fe}$, FA, FG, and FAG}

Table 2 shows the contents of G, Fe, FA, FG, and FAG in the samples prepared with graphite oxide, aluminum nitrate, and ferric nitrate. Figure $6 \mathrm{~b}$ shows that the graphene prepared under supercritical condition has the highest selectivity for $\mathrm{BD}, 89.7 \%$; however, the conversion ability is low, $16.9 \%$ (Fig. 6a). The conversion ability of Fe catalyst prepared under supercritical condition is much higher than graphene, but its selectivity is low, $40.5 \%$. The selectivity of catalyst FA is also low. When the catalyst is made with graphene, the selectivity obviously increased compared to the catalysts of $\mathrm{Fe}$ and FA by about 1.8 times. When using FA composite with graphene, its selectivity further increased, $87.38 \%$, approximately equal to that of graphene. The FAG sample has the maximum specific surface area in the five catalysts, where the dispersity of metal oxide particles increased. The particle diameter of $\mathrm{Fe}_{3} \mathrm{O}_{4}$ in the sample
Table 2 Preparation conditions of $\mathrm{G}, \mathrm{Fe}, \mathrm{FG}, \mathrm{FA}$, and $\mathrm{FAG}$

\begin{tabular}{lclllll}
\hline Sample & Graphite oxide $(\mathrm{g})$ & $\begin{array}{l}\text { Aluminum } \\
\text { nitrate }(\mathrm{g})\end{array}$ & Ferric nitrate $(\mathrm{g})$ & Alcohol $(\mathrm{mL})$ & $\begin{array}{l}\text { Tem- } \\
\text { perature } \\
\left({ }^{\circ} \mathrm{C}\right)\end{array}$ & Pressure $(\mathrm{MPa})$ \\
\hline $\mathrm{G}$ & 0.8064 & - & - & 70 & 300 & 11.0 \\
$\mathrm{Fe}$ & - & - & 6.0059 & 70 & 300 & 13.8 \\
$\mathrm{FG}$ & 0.4815 & - & 6.4651 & 70 & 300 & 13.8 \\
$\mathrm{FA}$ & - & 1.5059 & 3.2352 & 60 & 300 & 10.5 \\
FAG & 0.4810 & 1.5081 & 3.2286 & 60 & 300 & 11.8 \\
\hline
\end{tabular}




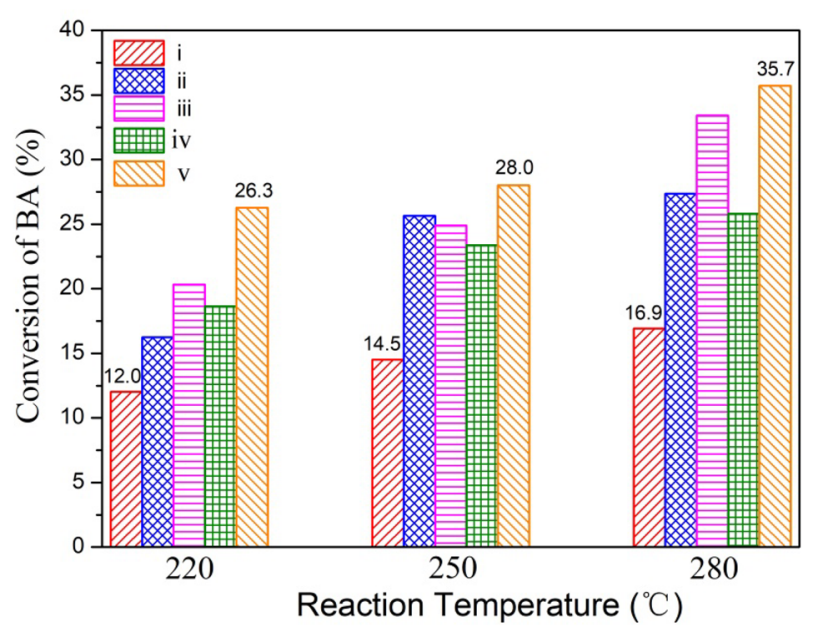

(a)

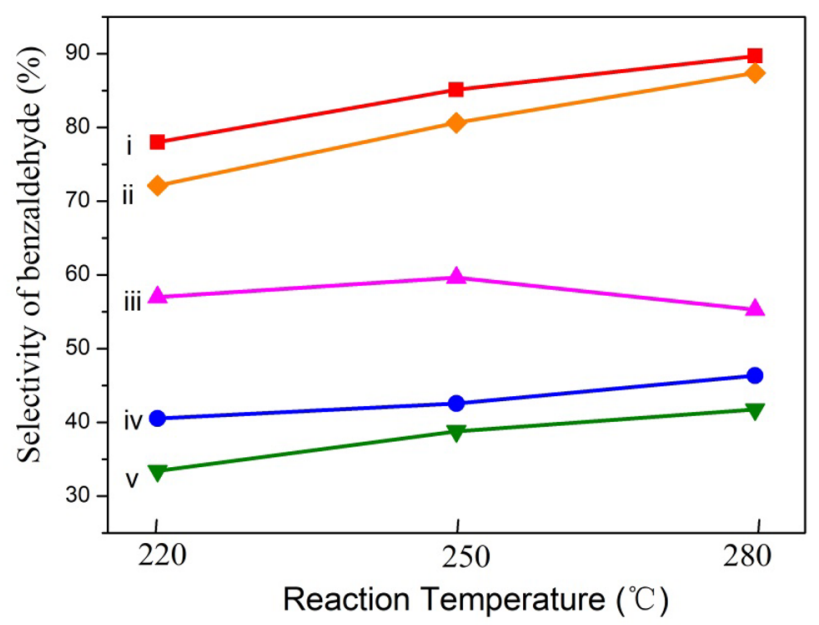

(b) is the smallest, and more active site is exposed during catalysis, thus leading to an excellent catalytic performance. When oxidants $\left(\mathrm{O}_{2}, \mathrm{H}_{2} \mathrm{O}_{2}(\mathrm{aq})\right.$ exist in the catalyst, the $\mathrm{Al}-\mathrm{O}-\mathrm{Fe}$ structure increases the reaction rate during oxidation [37].

\subsubsection{Effect of additive amount of graphene}

Table 3 shows the samples made with graphite oxide, aluminum nitrate, and ferric nitrate with a mass ratio of $0.04: 1: 2,0.08: 1: 2,0.16: 1: 2$, and 0.32:1:2, respectively. As shown Fig. 7, the conversion of BA slightly increased with the additive amount of graphene (Fig. 7a), but the selectivity of $\mathrm{BD}$ is obviously increased with the additive amount of graphene (Fig. 7b), where the crystalline phases of the sample are $\mathrm{Fe}_{3} \mathrm{O}_{4}$ and $\mathrm{G}$ (Fig. 1e). The graphene additive, which has a single layer of $\mathrm{sp}^{2}$-bonded carbon atoms arranged in a hexagonal honeycomb structure, contains a graphite skeleton, defects, and oxygen-containing groups, prevents FA to form a big particle between the particles due to the electrostatic interaction, and remains the FA particle dispersity. The $O$ in the oxygen-containing group acts as an intermediate oxygen species and catalyzes the reaction with a stronger oxidizing ability.The oxidation reaction rate of $B A$ mainly depends on two steps: One is the reaction rate controlling step, i.e., oxidation step of $B A$, and another is the activation of substrate $B A$ and the activation rate of molecular oxygen. Yang et al. [38] studied the activation process using electrochemistry and divided the oxidation reaction into two half-reactions, i.e., electrooxidation of $B A$ and electro-reduction of oxygen, indicating that $\mathrm{FeO}_{x}$ can obviously increase the activation ability of oxygen and thus increasing the catalytic activity. This is consistent with our results.

Fig. 6 Catalytic performance comparison between G, Fe, FA, FG, and FAG: a Conversion of BA: (i) G; (ii) Fe; (iii) FG; (iv) FA; (v) FAG; b selectivity of BD: (i) G; (ii) FAG; (iii) FG; (iv) Fe; (v) FA

Table 3 Preparation conditions of different additives of $G$

\begin{tabular}{|c|c|c|c|c|c|c|}
\hline Sample G:Al:Fe & Graphite oxide (g) & $\begin{array}{l}\text { Aluminum } \\
\text { nitrate }(\mathrm{g})\end{array}$ & Ferric nitrate (g) & Alcohol (mL) & $\begin{array}{l}\text { Temperature } \\
\left({ }^{\circ} \mathrm{C}\right)\end{array}$ & Pressure (MPa) \\
\hline $0.04: 1: 2$ & 0.0614 & 1.5026 & 3.2252 & 60 & 300 & 10.5 \\
\hline $0.08: 1: 2$ & 0.1214 & 1.4998 & 3.2614 & 60 & 300 & 10.5 \\
\hline $0.16: 1: 2$ & 0.2489 & 1.5019 & 3.2333 & 60 & 300 & 11.8 \\
\hline $0.32: 1: 2$ & 0.4810 & 1.5081 & 3.2286 & 60 & 300 & 11.8 \\
\hline
\end{tabular}




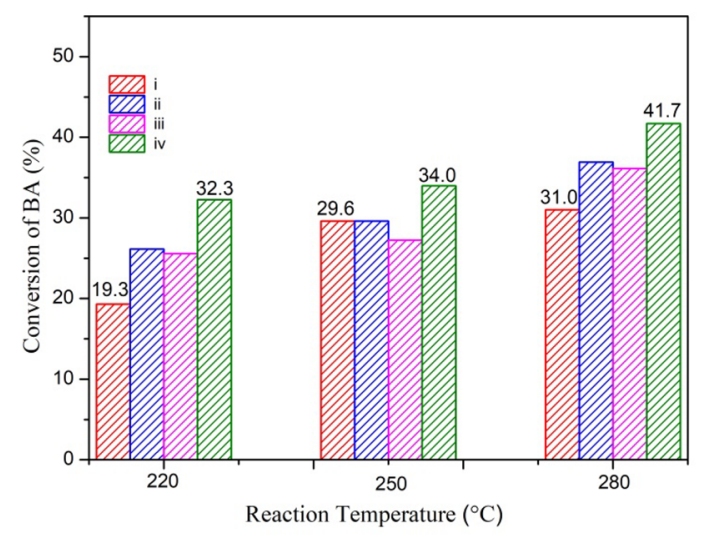

(a)

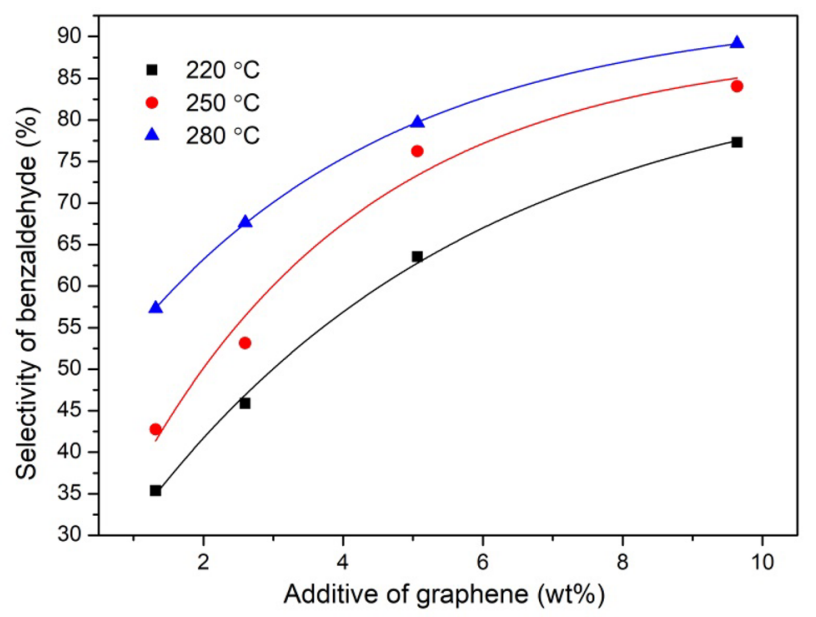

(b)

Fig. 7 Results of additive amount of graphene: a Conversion of BA: (i) $0.04: 1: 2$; (ii) $0.08: 1: 2$; (iii) $0.16: 1: 2$, and (iv) $0.32: 1: 2$ for G:Al:Fe. b Selectivity of BD

\subsubsection{Effect of $\mathrm{Al} / \mathrm{Fe}$ ratio}

To evaluate the effects of ratio of $\mathrm{Al}$ to $\mathrm{Fe}$, four samples were prepared with Al to Fe ratio of $0: 1,1: 1,1: 2$, and 1:3 (Table 4). As shown in Fig. 8, both the conversion rate of $\mathrm{BA}$ and selectivity of BD increased after the catalysts were doped with aluminum compared to without aluminum $(\mathrm{Al} / \mathrm{Fe}=0: 1)$. Because of the synergistic effect between $\mathrm{Al}$ and $\mathrm{Fe}$, the catalytic ability increased [39]. As shown in Fig. $8 b$, the selectivity of $B D$ is the best at a 1:2 ratio of Al to $\mathrm{Fe}$, although the value is not stable at $280^{\circ} \mathrm{C}$. The conversion ability of BA at $280^{\circ} \mathrm{C}$ is also good (Fig. 8a).

\subsubsection{Effect of temperature, pressure, and space velocity}

Two samples with content shown in Table 5 were evaluated at the preparation temperature of 300 and $400{ }^{\circ} \mathrm{C}$. In fact, the effect of temperature is not obvious for the conversion of BA (Fig. 9). The selectivity of BD increased with the catalyst preparation temperature, especially at a reaction temperature of $400^{\circ} \mathrm{C}$. Temperature can make $\mathrm{GO}$ completely and uniformly exfoliated by the interlayer expansion along the c-axis direction [25]. The interaction between graphene layers decreased. The oxygen-containing groups is more active, selectivity increased.

Under supercritical condition, three samples were prepared by adjusting the amount of absolute ethyl alcohol to control the reaction pressure (Table 6). As shown in Fig. 10a, the effect of preparation pressure for the conversion of $B A$ is not obvious, but the selectivity of BD obviously increased with the preparation pressure when the pressure is higher than $10 \mathrm{MPa}$ (Fig. 10b). The increase in preparation pressure promotes graphene exfoliation, and

Table 4 Preparation conditions of FAG at different Fe/Al ratios

\begin{tabular}{|c|c|c|c|c|c|c|}
\hline Sample Al:Fe & Graphite oxide (g) & $\begin{array}{l}\text { Aluminum } \\
\text { nitrate }(\mathrm{g})\end{array}$ & Ferric nitrate (g) & Alcohol (mL) & $\begin{array}{l}\text { Temperature } \\
\left({ }^{\circ} \mathrm{C}\right)\end{array}$ & Pressure (MPa) \\
\hline $0: 1$ & 0.4825 & - & 3.2364 & 60 & 300 & 11.0 \\
\hline $1: 1$ & 0.4842 & 3.0069 & 3.2320 & 60 & 300 & 11.8 \\
\hline $1: 2$ & 0.4810 & 1.5081 & 3.2286 & 60 & 300 & 11.8 \\
\hline $1: 3$ & 0.4826 & 1.0013 & 3.2386 & 60 & 300 & 10.2 \\
\hline
\end{tabular}




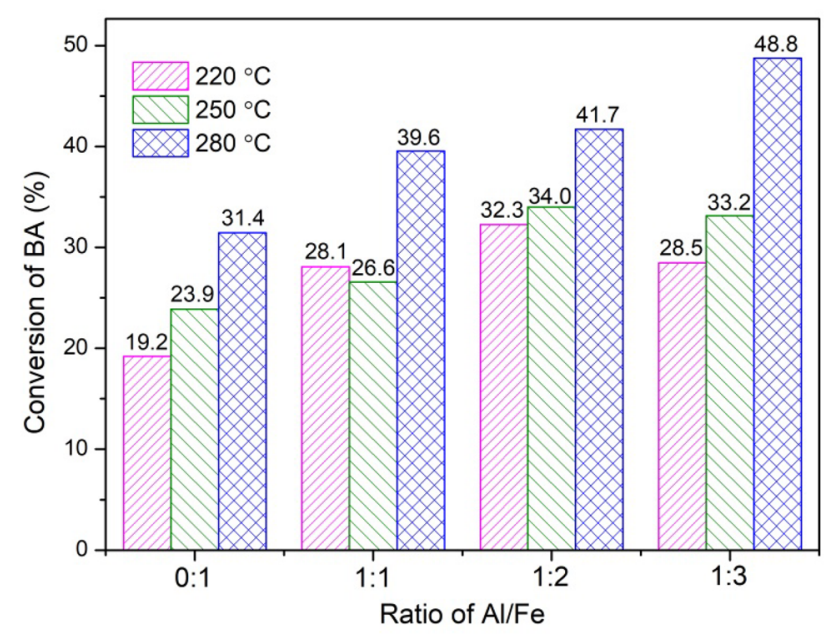

(a)

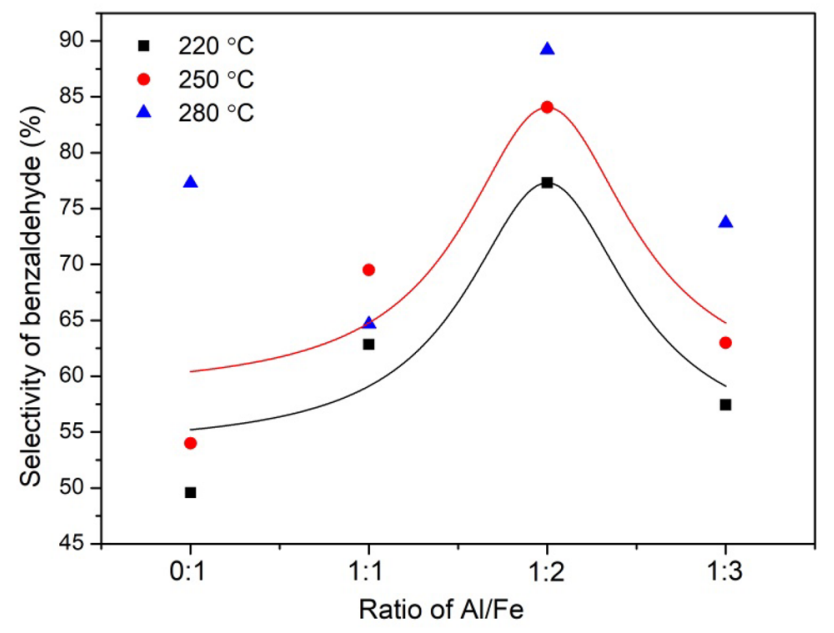

(b)

Fig. 8 Effect of Al/Fe ratio: a Conversion of BA. b Selectivity of BD the metal particles are uniformly dispersed on graphene, thus increasing the specific area.

Three samples were prepared under the same preparation conditions to evaluate the effects of space velocity on catalytic ability (Table 7). As shown in Fig. 11, in the case of a low space velocity of $3000 \mathrm{~mL} \mathrm{~h}^{-1} \mathrm{~g}^{-1}$, the conversion of BA increased with reaction temperature, but the selectivity of $\mathrm{BD}$ decreased with the reaction temperature, indicating that the sample at a low space velocity does not favor the conversion at a high reaction temperature. A low space velocity leads to a long contact time for the reaction sample with the catalyst so that over oxidation occurred and produced some byproducts such as benzoic acid. Thus, the selectivity of BD decreased. For the sample prepared at a space velocity of $6000 \mathrm{~mL} \mathrm{~h}^{-1} \mathrm{~g}^{-1}$ and $12,000 \mathrm{~mL} \mathrm{~h}^{-1} \mathrm{~g}^{-1}$, the selectivity of $\mathrm{BD}$ increased with reaction temperature, and a high space velocity is not favorable for the conversion of $B A$ and yield.

\section{Conclusions}

In this study, the physicochemical properties of FAG catalyst were studied. Using FAG as a catalyst for the oxidation of $B A$ to $B D$, the catalytic activity for the conversion of $B A$ and selectivity for $B D$ were also studied. The effects of additive amount of graphene, the ratio of $\mathrm{Al}$ to $\mathrm{Fe}$, preparation temperature, preparation pressure, and space velocity on FAG catalytic performance were studied. The following conclusions can be drawn based on the results of the study.

1. The addition of graphene to FA catalyst decreases the mutual friction between metal particles, thus decreasing the size of nanoparticles and increasing the specific area of catalyst. In the FAG sample, most of carbon is graphite carbon, $30.37 \%$ (at.), and most
Table 5 Preparation conditions of FAG at different temperatures

\begin{tabular}{lllllll}
\hline Sample & Graphite oxide $(\mathrm{g})$ & $\begin{array}{l}\text { Aluminum } \\
\text { nitrate }(\mathrm{g})\end{array}$ & Ferric nitrate $(\mathrm{g})$ & Alcohol $(\mathrm{mL})$ & $\begin{array}{l}\text { Tem- } \\
\text { perature } \\
\left({ }^{\circ} \mathrm{C}\right)\end{array}$ & Pressure $(\mathrm{MPa})$ \\
\hline S-300 & 0.4836 & 3.0009 & 3.2391 & 50 & 300 & 10.0 \\
S-400 & 0.4816 & 3.0013 & 3.2358 & 50 & 400 & 20.0
\end{tabular}




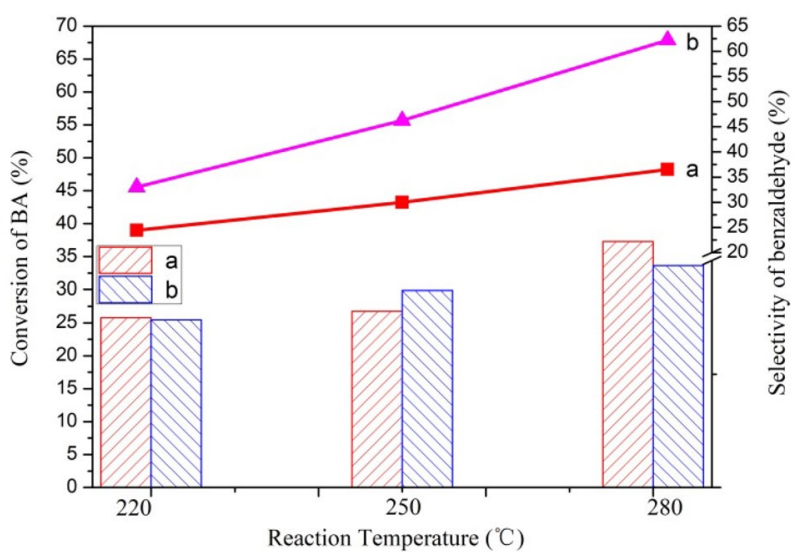

Fig. 9 Effects of preparation temperature for the conversion of BA (column graph) and selectivity of $\mathrm{BD}$ (line graph): (a) $300{ }^{\circ} \mathrm{C}$; (b) $400{ }^{\circ} \mathrm{C}$

of oxygen-containing functional group is $\mathrm{C}=\mathrm{O}, 6.77 \%$ (at.). By combining FA and graphene, the conversion of $B A$ and yield of $B D$ increased, and the selectivity of $\mathrm{BD}$ reached $87.38 \%$.

2. The addition of graphene to FA catalyst favors the formation of $\mathrm{Fe}_{3} \mathrm{O}_{4}$ crystalline phase and improves the catalytic performance. With the increase in the additive amount of graphene, the particle size decreased; the dispersion of nanoparticles of metal oxide increased; the catalyst specific area increased.

3. The addition of Al obviously promotes the conversion of BA and selectivity of BD. The selectivity of BD is affected by the $\mathrm{Al}$ to Fe ratio. When the ratio of $\mathrm{Al}$ to Fe is equal to 2 , the selectivity of $B D$ is the best.

4. The preparation temperature does not favor the increase in catalyst specific area; thus, the effect of preparation temperature for the conversion of $\mathrm{BA}$ is not obvious. The selectivity of BD increases with the increase in preparation temperature.

5. With the increase in preparation pressure, the extent of exfoliation increases, and the metal particles are uniformly dispersed on graphene, favoring the increase in catalyst specific area. The preparation pressure does not affect the conversion of BA. When the preparation

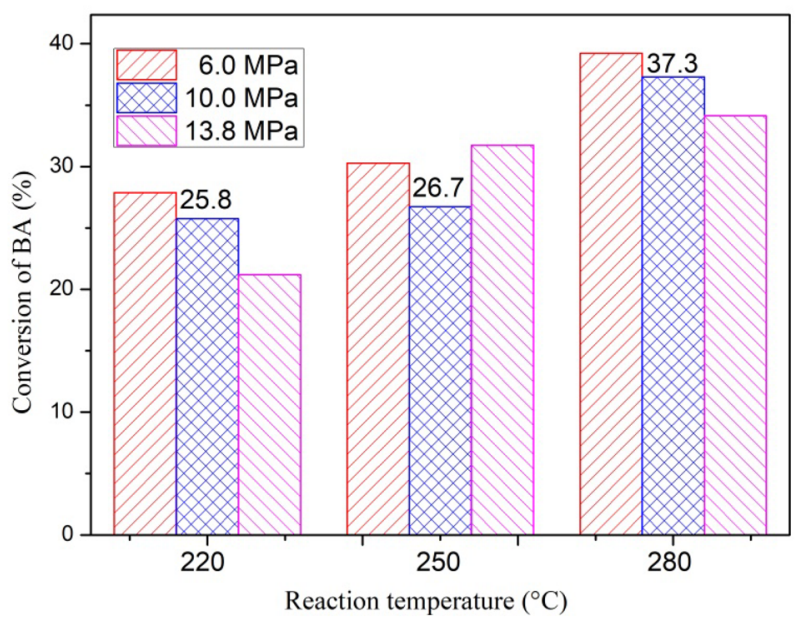

(a)

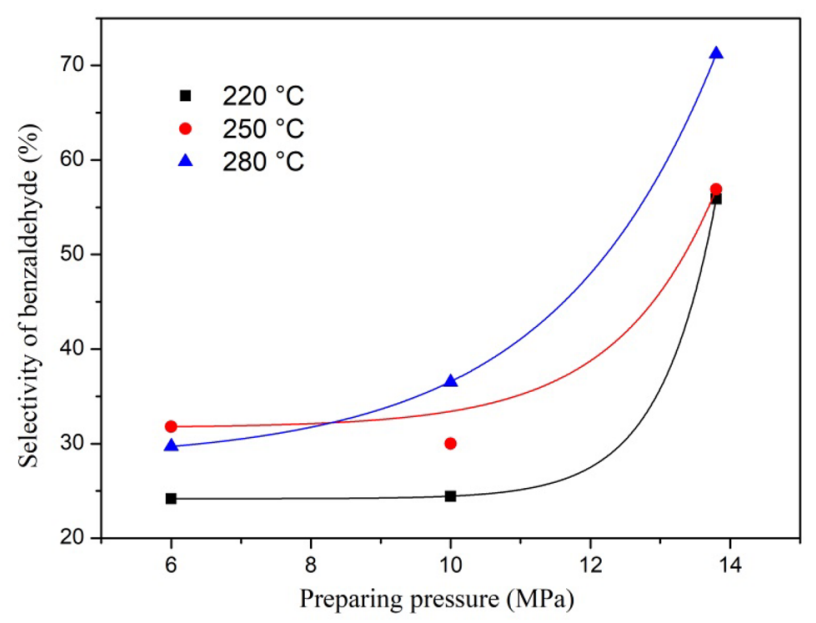

(b)

Fig. 10 Effects of pressure: a conversion of BA. b Selectivity of BD
Table 6 Preparation conditions of FAG at different pressures

\begin{tabular}{llllllr}
\hline Sample & Graphite oxide $(\mathrm{g})$ & $\begin{array}{l}\text { Aluminum } \\
\text { nitrate }(\mathrm{g})\end{array}$ & Ferric nitrate $(\mathrm{g})$ & Alcohol $(\mathrm{mL})$ & $\begin{array}{l}\text { Tem- } \\
\text { perature } \\
\left({ }^{\circ} \mathrm{C}\right)\end{array}$ & Pressure $(\mathrm{MPa})$ \\
\hline S-6.0 MPa & 0.4813 & 3.0066 & 3.2380 & 30 & 300 & 6.0 \\
S-10.0 MPa & 0.4836 & 3.0009 & 3.2391 & 50 & 300 & 10.0 \\
S-13.8 MPa & 0.4832 & 3.0018 & 3.2379 & 70 & 300 & 13.8 \\
\hline
\end{tabular}


Table 7 Preparation conditions at different space velocities

\begin{tabular}{lllllll}
\hline Sample & Graphite oxide $(\mathrm{g})$ & $\begin{array}{l}\text { Aluminum } \\
\text { nitrate }(\mathrm{g})\end{array}$ & Ferric nitrate $(\mathrm{g})$ & Alcohol $(\mathrm{mL})$ & $\begin{array}{l}\text { Tem- } \\
\text { perature } \\
\left({ }^{\circ} \mathrm{C}\right)\end{array}$ & Pressure $(\mathrm{MPa})$ \\
\hline S1 & 0.0611 & 0.7513 & 1.6159 & 60 & 300 & 10.5 \\
S2 & 0.0678 & 0.7525 & 1.6121 & 60 & 300 & 10.5 \\
S3 & 0.0629 & 0.7560 & 1.6186 & 60 & 300 & 10.2 \\
\hline
\end{tabular}

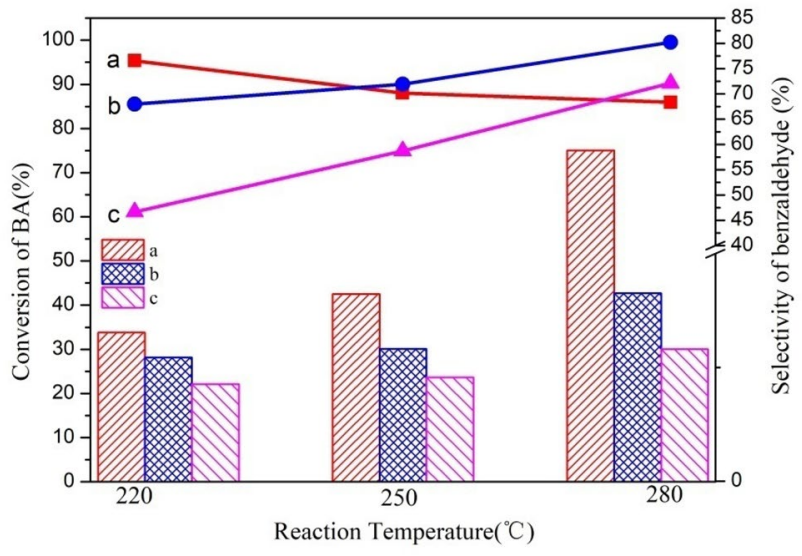

Fig. 11 Effects of space velocity for the conversion of BA (column graph) and the selectivity of BD (line graph): (a) $3000 \mathrm{~mL} \mathrm{~h}^{-1} \mathrm{~g}^{-1}$; (b) $6000 \mathrm{~mL} \mathrm{~h}^{-1} \mathrm{~g}^{-1}$; (c) $12,000 \mathrm{~mL} \mathrm{~h}^{-1} \mathrm{~g}^{-1}$

pressure is up to $13.8 \mathrm{MPa}$, the selectivity of $\mathrm{BD}$ is doubled.

6. A low space velocity leads to a long contact time for reaction sample with catalyst and leads to over oxidation, and the selectivity of BD decreases. A higher space velocity is not favorable for the conversion of $\mathrm{BA}$ and yield.

Acknowledgements The authors are grateful to the National Natural Science Foundation of China (Grant No. 21706165) and Scientific Research Fund of Liaoning Provincial Education Department, China (Grant No. LQ2019007).

\section{Declaration}

Conflict of interest There are no conflicts of interest to declare.

Open Access This article is licensed under a Creative Commons Attribution 4.0 International License, which permits use, sharing, adaptation, distribution and reproduction in any medium or format, as long as you give appropriate credit to the original author(s) and the source, provide a link to the Creative Commons licence, and indicate if changes were made. The images or other third party material in this article are included in the article's Creative Commons licence, unless indicated otherwise in a credit line to the material. If material is not included in the article's Creative Commons licence and your intended use is not permitted by statutory regulation or exceeds the permitted use, you will need to obtain permission directly from the copyright holder. To view a copy of this licence, visit http://creativecommons. org/licenses/by/4.0/.

\section{References}

1. Dimitratos N, Lopez-Sanchez JA, Morgan D et al (2007) Solvent free liquid phase oxidation of benzyl alcohol using Au supported catalysts prepared using a sol immobilization technique. Catal Today 122:317-324. https://doi.org/10.1016/j.cattod.2007. 01.002

2. Schultz MJ, Adler RS, Zierkiewicz W et al (2005) Using mechanistic and computational studies to explain ligand effects in the palladium-catalyzed aerobic oxidation of alcohols. J Am Chem Soc 127:8499-8507. https://doi.org/10.1021/ja050949r

3. Lee $M$, Chang S (2000) Highly efficient aerobic oxidation of benzylic and allylic alcohols by a simple catalyst system of $[\mathrm{RuCl} 2$ (pcymene) $]_{2} / \mathrm{Cs}_{2} \mathrm{CO}_{3}$. Tetrahedron Lett 41:7507-7510. https://doi. org/10.1016/S0040-4039(00)01284-3

4. Ming-Lin G, Hui-Zhen L (2007) Selective oxidation of benzyl alcohol to BD with hydrogen peroxide over tetra-alkylpyridinium octamolybdate catalysts. Green Chem 9:421-423. https:// doi.org/10.1039/B700534B

5. Li L, Zhao J, Yang J et al (2015) A sintering-resistant $\mathrm{Pd} / \mathrm{SiO}_{2}$ catalyst by reverse-loading nano iron oxide for aerobic oxidation of benzyl alcohol. RSC Adv 5:4766-4769. https://doi.org/10.1039/ C4RA14498H

6. Du Z, Ma J, Ma H et al (2010) Vanadyl sulfate: a simple catalyst for oxidation of alcohols with molecular oxygen in combination with 2,2,6,6-tetramethyl-piperidyl-1-oxyl. Catal Commun 11:732-735. https://doi.org/10.1016/j.catcom.2010.02.004

7. Du Z, Ma J, Ma H et al (2010) Synergistic effect of vanadiumphosphorus promoted oxidation of benzylic alcohols with molecular oxygen in water. Green Chem 12:590-592. https:// doi.org/10.1039/B924602A

8. Gopinath S, Kumar G, Narayanan S, Ragupathi C, Shravan Kumar S, Sivakumar K, Saravanan K, Ambika S (2019) Improved catalytic performance of cobalt oxide for selective oxidation of benzyl alcohol. SN Appl Sci 1:1-8. https://doi.org/10.1007/ s42452-019-0549-6

9. Gross J, Tauber K, Fuchs M et al (2014) Aerobic oxidation of isosorbide and isomannide employing TEMPO/laccase. Green Chem 16:2117-2121. https://doi.org/10.1039/C3GC41855C

10. Ntainjua EN, Piccinini M, Freakley SJ et al (2012) Direct synthesis of hydrogen peroxide using $\mathrm{Au}-\mathrm{Pd}$-exchanged and supported heteropolyacid catalysts at ambient temperature using water as solvent. Green Chem 14:170-181. https://doi.org/10.1039/ C1GC15863E

11. da Silva MJ, Julio AA, Dorigetto FCS (2015) Solvent-free heteropolyacid-catalyzed glycerol ketalization at room temperature. RSC Adv 5:44499-44506. https://doi.org/10.1039/C4RA17090C 
12. Seddon K, Stark A (2002) Selective catalytic oxidation of benzyl alcohol and alkylbenzenes in ionic liquids. Green Chem 4:119123. https://doi.org/10.1039/B111160B

13. Köckritz A, Sebek M, Dittmar A et al (2006) Ru-catalyzed oxidation of primary alcohols. J Mol Catal A Chem 246:85-99. https:// doi.org/10.1016/j.molcata.2005.10.020

14. Wang L, Weng Y, Duan P, Liu X, Wang X, Zhang Y, Wang C, Liu Q, Ma $L$ (2019) Influence of acid pretreatment on the hydrodeoxygenation performance of carbon supported RuMo bimetallic catalysts on sorbitol conversion. SN Appl Sci 1:1-10. https://doi. org/10.1007/s42452-019-0434-3

15. Biella S, Rossi M (2003) Gas phase oxidation of alcohols to aldehydes or ketones catalysed by supported gold. Chem Commun 378-379. https://doi.org/10.1039/B210506C

16. Gualteros JAD, Garcia MAS, da Silva AGM et al (2019) Synthesis of highly dispersed gold nanoparticles on $\mathrm{Al}_{2} \mathrm{O}_{3}, \mathrm{SiO}_{2}$, and $\mathrm{TiO}_{2}$ for the solvent-free oxidation of benzyl alcohol under low metal loadings. J Mater Sci 54:238-251. https://doi.org/10.1007/ s10853-018-2827-x

17. Miao Z, Zhou J, Li Z et al (2017) Ordered mesoporous chromium-zirconium oxophosphate composites with homogeneously dispersed chromium oxide: synthesis, characterization and application in liquid phase oxidation of benzyl alcohol and ethylbenzene. J Mater Sci 52:12141-12155. https://doi.org/10. 1007/s10853-017-1387-9

18. Su C, Loh KP (2013) Carbocatalysts: graphene oxide and its derivatives. Acc Chem Res 46:2275-2285. https://doi.org/10. 1021/ar300118v

19. Navalon S, Dhakshinamoorthy A, Alvaro M, Garcia H (2014) Carbocatalysis by graphene-based materials. Chem Rev 114:61796212. https://doi.org/10.1021/cr4007347

20. Fan $X$, Zhang $G$, Zhang $F$ (2015) Multiple roles of graphene in heterogeneous catalysis. Chem Soc Rev 44:3023-3035. https:// doi.org/10.1039/C5CS00094G

21. $\mathrm{Hu} \mathrm{H}, \mathrm{Xin} \mathrm{JH,} \mathrm{Hu} \mathrm{H} \mathrm{et} \mathrm{al} \mathrm{(2015)} \mathrm{Metal-free} \mathrm{graphene-based} \mathrm{cata-}$ lyst-Insight into the catalytic activity: a short review. Appl Catal A 492:1-9. https://doi.org/10.1016/j.apcata.2014.11.041

22. Su DS, Perathoner S, Centi G (2013) Nanocarbons for the development of advanced catalysts. Chem Rev 113:5782-5816. https://doi.org/10.1021/cr300367d

23. P. Serp JLF, (2009) Carbon materials for catalysis. Hoboken, New Jersey and Canada

24. Yang J-H, Sun G, Gao Y et al (2013) Direct catalytic oxidation of benzene to phenol over metal-free graphene-based catalyst. Energy Environ Sci 6:793-798. https://doi.org/10.1039/C3EE2 3623D

25. Long J, Xie X, Xu J et al (2012) Nitrogen-doped graphene nanosheets as metal-free catalysts for aerobic selective oxidation of benzylic alcohols. ACS Catal 2:622-631. https://doi.org/ $10.1021 / \operatorname{cs} 3000396$

26. Cheng W, Liu X, Li N et al (2018) Boron-doped graphene as a metal-free catalyst for gas-phase oxidation of benzyl alcohol to BD. RSC Adv 8:11222-11229. https://doi.org/10.1039/C8RA0 $0290 \mathrm{H}$

27. Huang H, Chen H, Sun D, Wang X (2012) Graphene nanoplatePt composite as a high performance electrocatalyst for direct methanol fuel cells. J Power Sources 204:46-52. https://doi.org/ 10.1016/j.jpowsour.2012.01.023

28. Zheng L, Zhang G, Zhang M et al (2012) Preparation and capacitance performance of $\mathrm{Ag}$-graphene based nanocomposite. J
Power Sources 201:376-381. https://doi.org/10.1016/j.jpowsour. 2011.11.026

29. Jiang D-H, Yang C-H, Tseng C-M et al (2014) Metal/graphene nanocomposites synthesized with the aid of supercritical fluid for promoting hydrogen release from complex hydrides. Nanoscale 6:12565-12572. https://doi.org/10.1039/C4NR0 3357D

30. Moma J, Baloyi J, Ntho T (2018) Synthesis and characterization of an efficient and stable Al/Fe pillared clay catalyst for the catalytic wet air oxidation of phenol. RSC Adv 8:30115-30124. https://doi.org/10.1039/C8RA05825C

31. Liu J, Fu S, Yuan B et al (2010) Toward a universal "adhesive nanosheet" for the assembly of multiple nanoparticles based on a protein-induced reduction/decoration of graphene oxide. J Am Chem Soc 132:7279-7281. https://doi.org/10.1021/ja100 938r

32. Zhu G, Liu Y, Xu Z et al (2010) Flexible magnetic nanoparticlesreduced graphene oxide composite membranes formed by selfassembly in solution. ChemPhysChem 11:2432-2437. https:// doi.org/10.1002/cphc.201000227

33. Li S, Ge X, Jiang S et al (2015) Synthesis of octahedral and cubic $\mathrm{Cu}_{2} \mathrm{O}$ microcrystals in sub- and super-critical methanol and their photocatalytic performance. J Mater Sci 50:4115-4121. https:// doi.org/10.1007/s10853-015-8967-3

34. Choi M, Koppala SK, Yoon D et al (2016) A route to synthesis molybdenum disulfide-reduced graphene oxide (MoS2-RGO) composites using supercritical methanol and their enhanced electrochemical performance for Li-ion batteries. J Power Sources 309:202-211. https://doi.org/10.1016/j.jpowsour.2016. 01.081

35. Tang L, Wang Y, Li Y et al (2009) Preparation, structure, and electrochemical properties of reduced graphene sheet films. Adv Func Mater 19:2782-2789. https://doi.org/10.1002/adfm.20090 0377

36. Zhang Y, Tian J, Li H et al (2012) Biomolecule-assisted, environmentally friendly, one-pot synthesis of CuS/reduced graphene oxide nanocomposites with enhanced photocatalytic performance. Langmuir 28:12893-12900. https://doi.org/10.1021/ la303049w

37. Obermayer D, Balu AM, Romero AA et al (2013) Nanocatalysis in continuous flow: supported iron oxide nanoparticles for the heterogeneous aerobic oxidation of benzyl alcohol. Green Chem 15:1530-1537. https://doi.org/10.1039/C3GC40307F

38. Zhou C, Chen Y, Guo Z et al (2011) Promoted aerobic oxidation of benzyl alcohol on CNT supported platinum by iron oxide. Chem Commun 47:7473-7475. https://doi.org/10.1039/C1CC12264A

39. Li Q, Zhang L, Wang $X$ et al (2017) Color conversion of the magnetically separable $\mathrm{Al} / \mathrm{Fe}$ oxide RNGO in the selective oxidation of benzyl alcohol induced the observation of its morphology change. RSC Adv 7:37467-37473. https://doi.org/10.1039/ C7RA03527F

Publisher's Note Springer Nature remains neutral with regard to jurisdictional claims in published maps and institutional affiliations. 